\title{
Anal Column
}

National Cancer Institute

\section{Source}

National Cancer Institute. Anal Column. NCI Thesaurus. Code C32067.

The longitudinal folds present in the upper part of the anal canal. 